\title{
Dynamic Characteristics of Fault Structure and Its Controlling Impact on Rock Burst in Mines
}

\author{
Tianwei Lan, ${ }^{1,2}$ Jiawei Sun $\mathbb{D}^{1},{ }^{1}$ A. S. Batugin, ${ }^{3}$ Wenqi Zhao, ${ }^{1}$ Mancang Zhang, \\ Weidong Jia, ${ }^{1}$ and Zhijia Zhang ${ }^{1}$ \\ ${ }^{1}$ College of Mining, Liaoning Technical University, Fuxin 123000, China \\ ${ }^{2}$ Key Laboratory of Mining Disaster Prevention and Control, Qingdao 266590, China \\ ${ }^{3}$ Moscow Mining Institute, National Research University of Process Technology (MISIS), Moscow 119991, Russia \\ Correspondence should be addressed to Jiawei Sun; sjw2318@163.com
}

Received 30 April 2021; Accepted 29 June 2021; Published 12 July 2021

Academic Editor: Junfei Zhang

Copyright (c) 2021 Tianwei Lan et al. This is an open access article distributed under the Creative Commons Attribution License, which permits unrestricted use, distribution, and reproduction in any medium, provided the original work is properly cited.

As one of the most serious shock dynamic disasters in coal mining, rock burst only occurs under the certain geodynamic environment. Geodynamic is the necessary requirement for the occurrence of rock burst, and the disturbance of mining engineering is the sufficient requirement. In terms of the fault structure, the method of geodynamic zoning is used to classify fault structure forms of rock burst in mines, and a model of geological structure is established to reveal the connection between fault structure and mine engineering. Besides, the influence of fault structure on rock burst is analyzed, and the controlling mechanism of the fault structure on the tectonic evolution of the mine area and the occurrence of rock burst is revealed. This research provides a treatment plan for the prediction and prevention of rock burst and guides the safe production in the coal mining engineering.

\section{Introduction}

Rock burst is a typical shock dynamic disaster in coal mines. When the coal-rock mechanical system reaches the ultimate strength, the elastic energy is released in a sudden, sharp, and violent form, namely, the rock burst. It leads to the instantaneous destruction of coal-rock stratum with the impact of pulverized coal, resulting in the roadway destruction and casualty accidents. Statistically, there are 329 mines with bump-prone property (including closed and non-stateowned mines) in China, 253 of which are being mined and distributed in 26 provinces, municipalities, and autonomous regions [1]. As the depth of mining increases, physical properties, medium, stress, gas, and other factors of coal and rock mass have been changed significantly compared with those in the shallow mining, and the intensity and frequency of rock burst tend to increase [2-7].

In the field of rock mechanics, abundant achievements have been made in the study of rock burst, while the theory of universal applicability has not been formed. The existing rock burst mechanism is essentially developed on the basis of early strength theory, stiffness theory, energy theory, and rock burst orientation theory [8-12]. Recently, big data, cloud computing, Internet of Things, and artificial intelligence are applied to the prediction and prevention of rock burst in the mine. These methods of CT scanning, 3D printing, and $3 \mathrm{D}$ numerical simulation are employed to reveal the rock burst formation under dynamic and static loads on meso-scale, experimental scale, and engineering scale $[13,14]$. The study on the mechanism of instability and evolution of coal-rock structures under the rock burst has become a hot topic in academic research.

Current research is mainly concentrated on the mechanism, prediction, monitoring, and prevention of rock burst, as well as the experimental and theoretical research on the strength and failure characteristics of coal-rock structure [15-17]. However, there are few studies on the dynamic environment and geodynamic states of the mine from the macroperspective.

The geological environment of the mine is in the plate structure, and the occurrence of shock dynamic disasters such as rock burst is related to the plate movement. Based on 
the analysis of the geodynamic environment and the theory of geodynamic zoning, a model of geological structure is established in accordance with the time relationship between plate structure and mine engineering. Through the analysis of fault structure effect on rock burst in the mine, the controlling machine of fault structure on rock burst is illustrated in this paper. It provides a theoretical basis and guidance for the prediction and prevention of rock burst in mining.

\section{Geodynamic Environment and Geodynamic State of Mines}

2.1. Geodynamic Environment. China mainland is situated in the southeastern part of the Eurasian plate. Eastern Chinese continent is affected by the subduction and subtraction of the western Pacific and Philippine plates. The western and southwestern parts are affected by the collision between the Indian plate and the Eurasian plate. The acting force from the plate boundary is the main source of tectonic deformation and energy accumulation in the Cenozoic and present China. Mining areas are situated in the plate tectonic body. The geological body of the mine is controlled by the huge geodynamic environment system of plate tectonic. Tectonic stress and energy produced by collision and extrusion between plates are transferred to the secondary subplates, tectonic blocks, and engineering areas for coal mining through the crustal rock mass medium. Mining activity is affected and controlled by the geodynamic environment (Figure 1).

To study the shock dynamic disasters such as rock burst in the process of coal mining, it is necessary to analyze and evaluate the geodynamic environment of the mine [18]. Indepth systematic research on the geodynamic environment of the mine is essential to explain the mechanism of rock burst so as to take effective prevention and controlling measures.

2.2. Geodynamic States in the Mine. According to the theory of geodynamic zoning, the occurrence of rock burst in mines must have corresponding geodynamic environment, which is the interactive result of natural geodynamic and engineering disturbance. Only with the geodynamic environment of rock burst in mines and under the influence of human engineering activities, rock burst can occur. It can be concluded that the geodynamic state is the necessary requirement for the occurrence of mine dynamic disasters, and the mining disturbance is the sufficient requirement [19].

There are many factors influencing rock burst in the geodynamic environment, including fault tectonic movement, tectonic geomorphology, tectonic stress, fault structure, mining depth of coal seam, overlying hard rock states, area criterion, as well as coal and rock medium, surrounding rock structure, water-bearing states of coal and rock mass, gas, temperature, and seepage states. The main controlling factor of rock burst is the geodynamic state. Because of the difference of regional geological and dynamic environment in different mines, the main controlling factors of rock burst are different, resulting in different intensies of rock burst. This can also explain why rock burst disasters never occur in some mining areas, while frequently occur in other mining areas.

2.3. Fault Structure. Fault structure is the main controlling factor for rock burst in the mine. Fault tectonics is a phenomenon in which geological bodies break up during crustal tectonic movement, resulting in the loss of continuity and integrity. Statistically, there are 98 mines with bump-prone property in China, $93.8 \%$ of them have large geological fault structures around them. The closer distance between the mine to the fault structure, the greater the frequency and intensity of rock burst. It can be concluded that the fault structure plays an important role in controlling the rock burst and is an important index to evaluate the mine geodynamic environment.

According to the theory of geodynamic zoning, fault structure is not only an objective geological body but also a trend of tectonic movement and a potential active fault [20-22]. From the perspective of the distribution of fault structure determined by geodynamic zoning and mine with the bump-prone property, the occurrence of rock burst is closely related to the scale and activity of fault structure. Rock burst mostly occurs near the fault zone and frequently in the intersection of multiple fault zones. Therefore, the fault structure determined by the geodynamic zoning method can be used as the basis for the analysis and evaluation of rock burst.

\section{Geodynamic Zoning Method for the Division of Fault Structure}

3.1. Geodynamic Zoning Method. Based on plate tectonic dynamics and natural factors such as topography, the method of geodynamic zoning follows the principle from the whole to the local. Taking the mine mining engineering area as the research object, geodynamic zoning is used to classify the fault structure as I-V grade (see Table 1) on the topographic maps of different scales. To determine the fault structure distribution and shock dynamic characteristics in the mining area, a model of geological structure is established with the actual connection between plate tectonics and mine engineering, providing geological environment information for mining and shock dynamic hazard prediction [23-25].

\subsection{Geomorphological Characteristics for the Division of Fault} Structures. On the one hand, tectonic stress of the crustal rock mass is changed by the crustal tectonic movement; on the other hand, geological structures such as faults are produced. The tectonic movement often occurs along the fault structure. Thus, severe earthquakes, tsunamis, and volcanic eruptions often occur near the fault structure. For the geological body of coal mining, the stress concentration area and the dynamic disaster concentration area such as rock burst are near the fault structure. In the process of crustal movement, there are traces of tectonic 


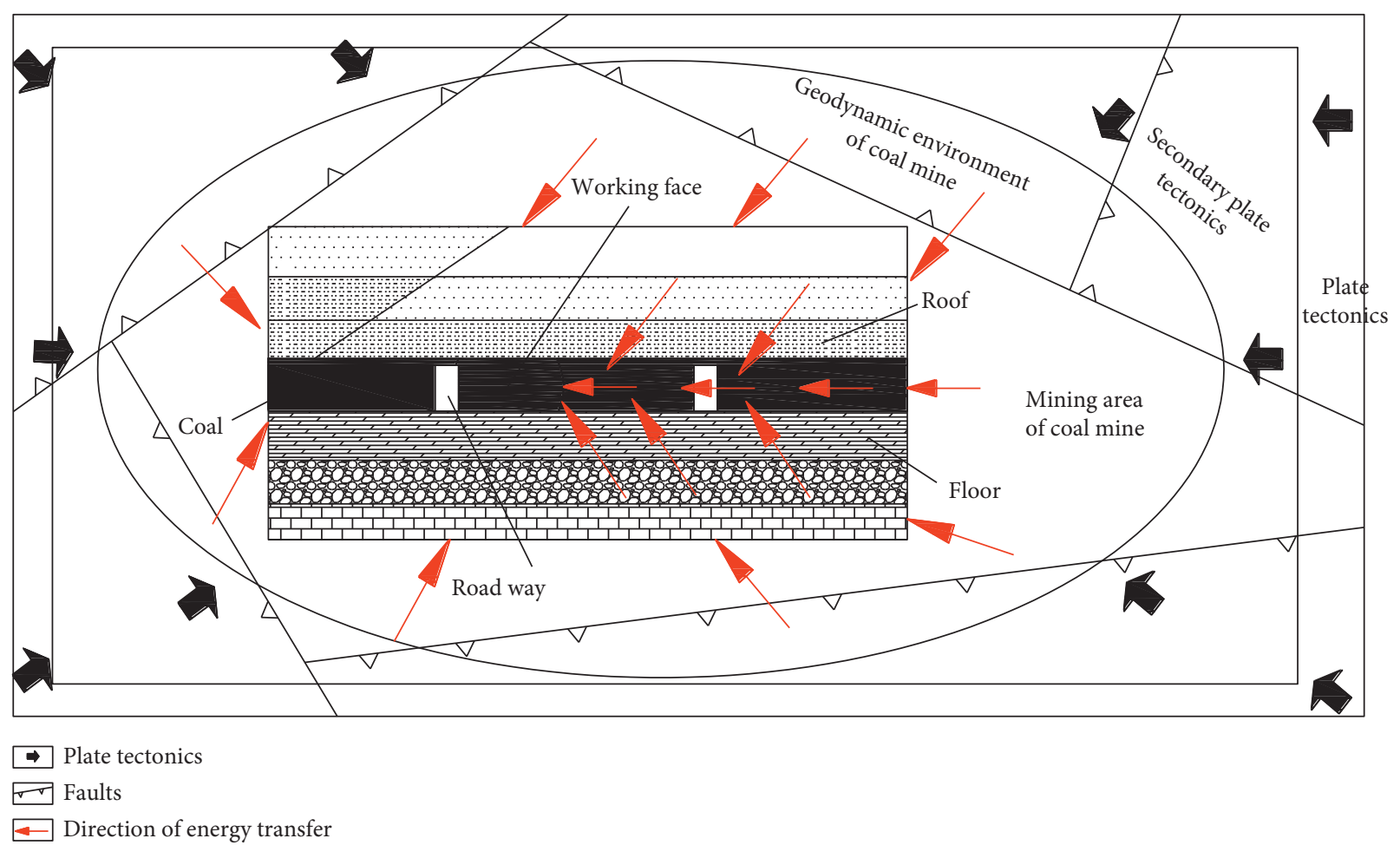

FIGURE 1: Geodynamic environment of the mine.

TABLE 1: Proportional range of fault blocks in geodynamic zoning.

\begin{tabular}{lccc}
\hline No. & Fault structure & Fault grade & Scale of topographic map \\
\hline 1 & Fault block & I & $1: 2.5$ million \\
2 & Fault block & II & $1: 1$ million \\
3 & Fault block & III & $1: 250,000-1: 100,000$ \\
4 & Fault block & IV & $1: 50,000-1: 25,000$ \\
5 & Fault block & V & $1: 10,000$ \\
\hline
\end{tabular}

movement on the surface, such as elevation difference of adjacent fault blocks, topography, valleys, cliffs, river systems, oceans, and lakes. They are all traces of tectonic movement on the surface of the crust. Although some tectonic and geomorphological features are blurred due to the influence of surface weathering and erosion, the markers that can divide fault blocks and their boundaries still can be observed.

The geodynamic zoning method can be implemented to identify and classify fault structures according to the features of the geomorphologic traces left by crustal movement on the surface, combined with aerial satellite photographs and aerial photographs of unmanned aerial vehicles. The existence and activity of fault structures can be identified by field geological survey. Geomorphological features of the fault structure division are based on the geodynamic zoning (Figure 2).

According to geomorphological markers of fault structure, the same grade of elevation is divided into a fault block with a smooth curve on the $1: 2,500,000-1: 10,000$ topographic map. The smooth curve is the boundary of the fault block, namely, the fault structure determined by the geodynamic zoning. The former grade of the fault structure division on the topographic map is regarded as the boundary constraint condition of latter grade of the fault block structure division. The fault block division is carried out on the latter topographic map whose the fault structure is determined. By analogy, fault blocks and structures associated with mine engineering are finally determined. The existence of fault structure objectively reflects the tectonic movement and stress field in the engineering area of the mine.

3.3. Geomorphological Characteristics for the Division of Fault Structures. To divide two different adjacent areas into different blocks, it is necessary to consider the elevation difference between adjacent areas. It is concluded in the geodynamic zoning that the average height difference is $200 \mathrm{~m}$ for young mountain systems, $100 \mathrm{~m}$ for eroded mountain systems and mountains of medium height, and $50 \mathrm{~m}$ for eroded hills of medium height, uplift areas of anticline, or young depression areas. The average height difference is $20-25 \mathrm{~m}$ for the structural depression covered by the erosion process.

For the specific area, the minimum elevation difference $\Delta h_{\min }$ can be calculated by (1). Considering the mechanical damage, the permeability during AF-ECBM recovery can be expressed as follows:

$$
\Delta h_{\min }=0.1\left(H_{\max }-H_{\min }\right),
$$

where $H_{\max }$ is the maximum absolute height of the peak surface, $m$, and $H_{\min }$ is the minimum absolute height of the peak surface, $m$. Generally, the empirical value of the 


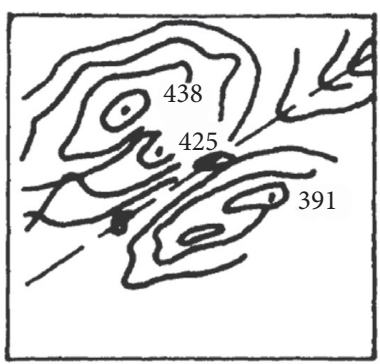

(a)

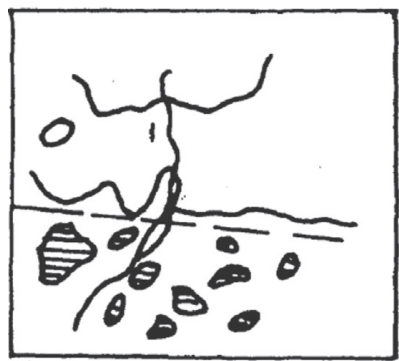

(e)

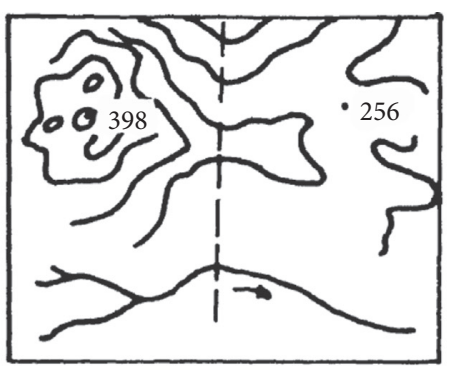

(b)

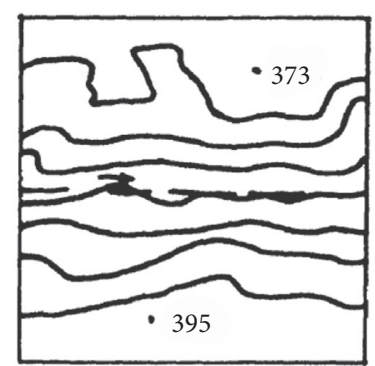

(c)

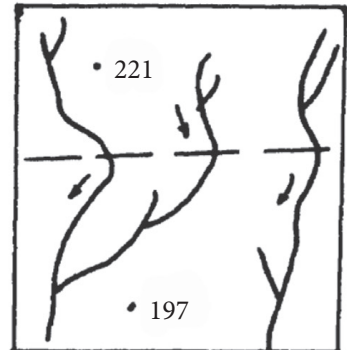

(d)

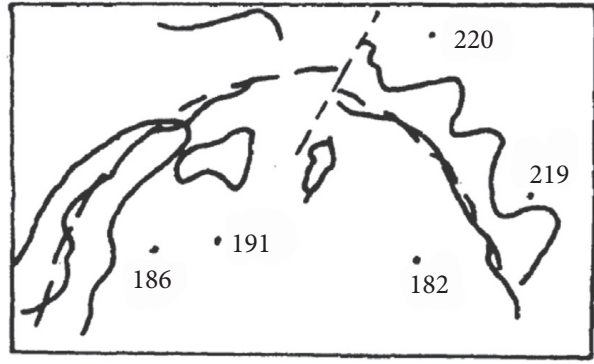

(f)

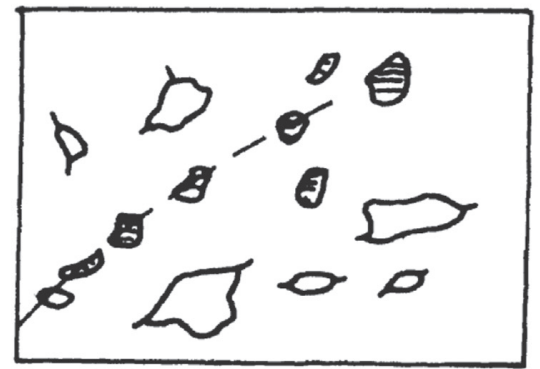

(g)

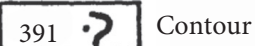
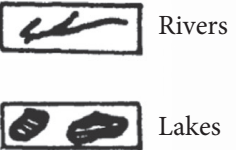

- - Geomorphological faults

FIGURE 2: Geomorphological characteristics of fault structures: (a) contour drop; (b) geomorphology and riverbed changes; (c) intermountain canyons; (d) bending trend of rivers; (e) landscape characteristics; (f) valleys with special contour; (g) lakes of linear shape.

minimum elevation difference $\Delta h_{\min }$ can be obtained according to Table 2 .

\section{Application Examples}

4.1. Analysis of 2.14 Rock Burst in Sunjiawan Coal Mine of Fuxin. On February 14, 2005, a huge gas explosion accident was caused by rock burst occurred in Sunjiawan Coal Mine, Fuxin, resulting in 214 deaths, 30 injuries, and a direct economic loss of 49.689 million yuan. The accident occurred in the return airway of preparation face 3316, with a design section of $10.2 \mathrm{~m}^{2}$. The return airway was supported by the combination of anchor, mesh, and cable.

The geodynamic zoning method is used to classify the I-V fault block of the Sunjiawan Coal Mine, and the connection between the mine project and the active fault block is established. As shown in Figure 3, there are 12 times of rock burst at working face 3315 and 3316 of Sunjiawan Coal Mine, which are all located near the IV-2 fault structure determined by the geodynamic zoning. IV -2 fault structure has a strong activity. Abnormal tectonic stress zones exist on both sides of the fault structure, forming high-stress zones and accumulating the energy easily. 2.14 rock burst accident occurred at the intersection of fault structure IV-2 and V-2, which belong to the complex-structure area and high-stress area. When mining approaches to the active fault, the original mechanical equilibrium state of the coal-rock system is destroyed, and the energy is released instantaneously, leading to the occurrence of rock burst accident.

4.2. Analysis of 3.1 Rock Burst in Yuejin Coal Mine of Yima. In Yuejin Coal Mine, rock burst occurred 38 times in No. 23 and No. 25 mining areas with a mining depth of 800-1050 m. Among them, there were 9 times of rock burst in the mining process in working face 25110. At 10:09:59 a.m of March 1, 2011, rock burst occurred in the roadway of working face 25110 with magnitude of 2.071 . A range of $210-410 \mathrm{~m}$ and a total of $200 \mathrm{~m}$ roadway were affected by the rock burst impact. Three workers were slightly injured by the rock burst.

The geodynamic zoning method is used to classify the I-V fault block of Yuejin Coal Mine. As shown in Figure 4, IV-7, IV-8, V-17, and V-18 are mainly related with the 3.1 
TABLe 2: Empirical value of minimum elevation difference in fault structure division.

\begin{tabular}{lccc}
\hline No. & Fault block grade & Topographic map scale & Least $z$-difference $\Delta h_{\text {min }}$ \\
\hline 1 & I & $1: 2.5$ million & $500 \mathrm{~m}$ \\
2 & II & $1: 1$ million & $200 \mathrm{~m}$ \\
3 & III & $1: 250,000-1: 100,000$ & $100 \mathrm{~m}$ \\
4 & IV & $1: 50,000-1: 25,000$ & $20-50 \mathrm{~m}$ \\
5 & V & $1: 10,000$ & $5-10 \mathrm{~m}$ \\
\hline
\end{tabular}

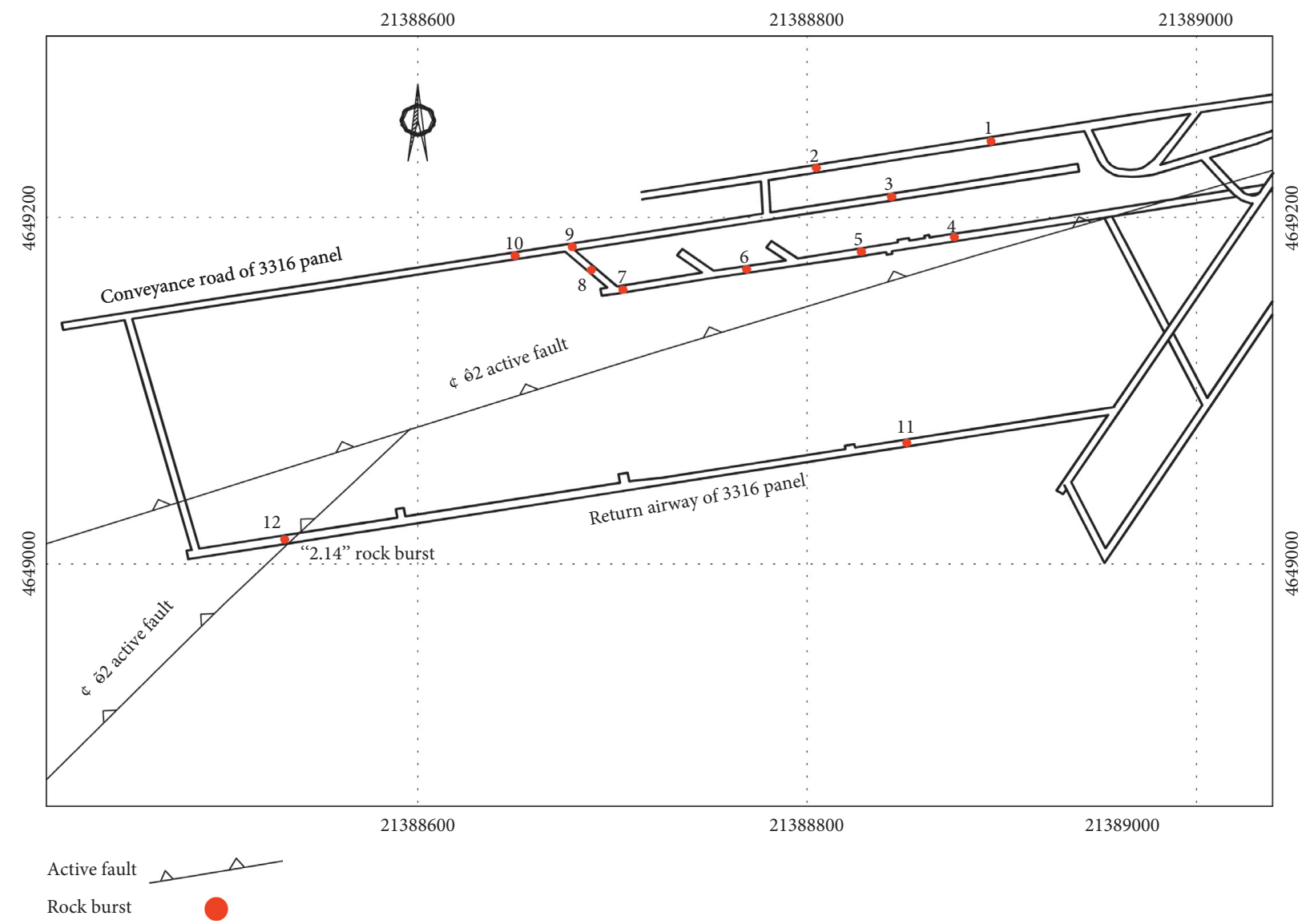

Figure 3: Positional relationships between 2.14 rock burst and fault structure in Sunjiawan Coal Mine.

rock burst accident in working face 25110 . The existence of these faults is the main controlling factor for the occurrence of rock burst. Shock dynamic influence areas exist in the fault, and its influence range varies with the grade. Meanwhile, fault structure has a weakening effect as the heterogeneous medium of rock mass. Hence, there are weakening influence areas around the fault. When the coal mining operation is carried out in this area, it is easy to induce the rock burst.

\subsection{Controlling Mechanism of Fault Structure on Rock Burst in} the Mine. The fault structure is the region with higher stress concentration in the current geostress field. At the same time, the continuous activity of the fault structure leads to stress redistribution in its vicinity. Therefore, high local tectonic stress concentration areas are often formed in specific parts of fault structure or fault block, and the concentration of tectonic stress leads to accumulation of elastic deformation potential. When the underground activity approaches to this area, the superposition of tectonic stress and mining stress destroys the original stress equilibrium state of coal and rock mass, and the accumulated elastic potential in coal and rock strata is suddenly released. When the released elastic energy is greater than the consumed energy, shock dynamic disasters such as mine rock burst occur.

Hence, the occurrence of rock burst in mine should have certain geodynamic environment. Rock burst is the result of the interaction of natural geodynamic and engineering disturbance. Stress concentration and energy accumulation near fault structures are the power source and energy basis of rock burst, and mining activities are inducing factors of rock burst. Therefore, the corresponding measures of local-risk relief and prevention should be taken in advance to prevent the rock burst when the excavation enters the affected area of the fault structure. 


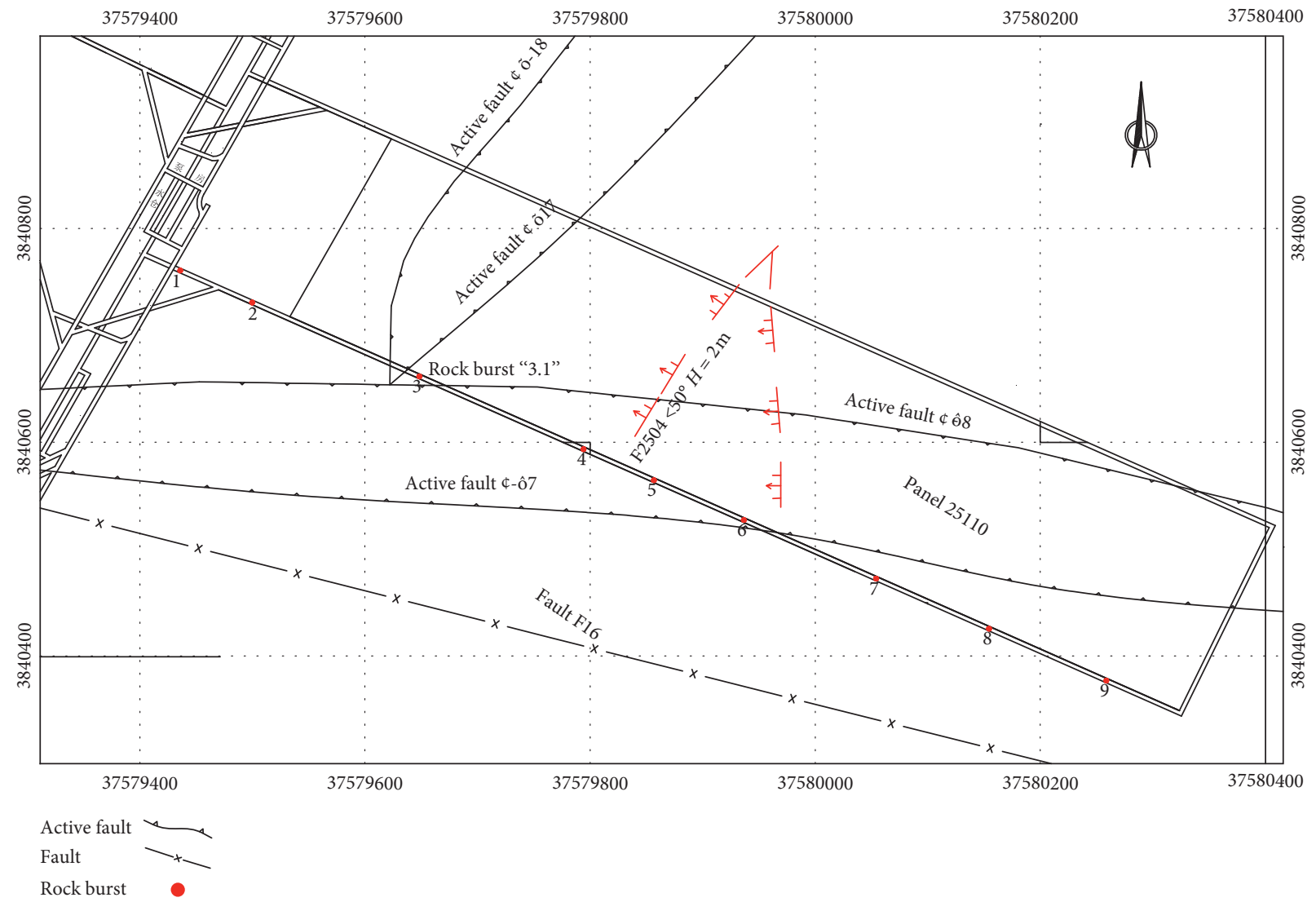

Figure 4: Positional relationship between 3.1 rock burst and fault structure in Yuejin Coal Mine.

\section{Conclusions}

Geodynamic is the necessary requirement for the occurrence of rock burst, and the disturbance of mining engineering is the sufficient requirement. The following conclusion can be obtained:

(1) Rock burst only occurs under the certain geodynamic environment. The geodynamic state is the necessary requirement for the occurrence of rock burst, and the disturbance of mining engineering is the sufficient requirement. Fault structure is one of main controlling factors in the geodynamic states of rock burst.

(2) According to geomorphological characteristics, grade I-V fault block structures are divided by using the geodynamic zoning method. A model of the geological structure model is established to reveal the connection between plate structure and mine. Through analyzing engineering examples of rock bursts in mines, it is concluded that there are tectonic stress concentration and energy accumulation near the fault structure. Under the dynamic influence zone of the fault structure and the weakening of the heterogeneous body, it is easy to induce the rock burst by the mining activities.
(3) To determine the geodynamic states and types of geodynamic environment of rock burst, the geodynamic zoning method can be used to evaluate the regional geodynamic environment of newly built mines. Besides, corresponding measures should be taken to relieve and prevent the rock burst in line with the results of the geodynamic zoning method.

\section{Data Availability}

The experimental data used to support the findings of this study are included within the article.

\section{Conflicts of Interest}

The authors declare that they have no conflicts of interest.

\section{Acknowledgments}

This research was financially supported by the LiaoNing Revitalization Talents Program (XLYC2007042), National Natural Science Foundation of China (51674139), Key Laboratory of Mining Disaster Prevention and Control (MDPC201926), and Liaoning Technical University Double First Class Discipline Innovation Team (LNTU20TD-03). 


\section{References}

[1] L. M. Dou, "Induced shock and control of hard roof," in Proceedings of the 37th International Conference on Ground Control in Ming, Morgantown, WV, USA, July-2018.

[2] Q. X. Qi, H. Y. Li, Z. G. Deng, S. K. Zhao, N. B. Zhang, and Z. W. Bi, "Studying of standard system and theory and technology of rock burst in domestic," Coal Mining Technology, vol. 22, no. 1, pp. 1-5, 2017.

[3] Y.S. Pan, "Integrated study on compound dynamic disaster of coal-gas outburst and rockburst," Journal of China Coal Society, vol. 41, no. 1, pp. 105-112, 2016.

[4] Y. D. Jiang, Y. S. Pan, F. X. Jiang, L. M. Dou, and Y. Ju, "State of the art review on mechanism and prevention of coal bumps in China," Journal of China Coal Society, vol. 39, no. 2, pp. 205-213, 2014.

[5] D. Ma, J. Zhang, H. Duan, Y. Huang, M. Li, and Q. Sun, "Reutilization of gangue wastes in underground backfilling mining: overburden aquifer protection," Chemosphere, vol. 264, no. 1, Article ID 128400, 2021.

[6] Q. X. Qi, Z. H. Ouyang, S. K. Hao, H. Y. Li, X. L. Li, and N. B. Zhang, "Study on types of rock burst mine and prevention methods in China," Coal Science and Technology, vol. 42, no. 10, pp. 1-5, 2014.

[7] Y. D. Jiang and Y. X. Zhao, "Istate of the art: investigation on mechanism, forecast and control of coal bumps in China," Chinese Journal of Rock Mechanics and Engineering, vol. 34, no. 11, pp. 2188-2204, 2015.

[8] N. G. W. Cook, E. Hoek, J. P. G. Pretorius et al., "Rock mechanics applied to the study of rock bursts," Journal of the South African Institute of Mining and Metallurgy, vol. 65, pp. 435-528, 1965.

[9] A. Petuhoff, "Theory of rockburst prevention and practice," in Proceedings of the 22nd International Conference on Mining Safety, Coal Industry Publishing House, Beijing, China, April 1987.

[10] M. T. Zhang, "Unity of rock burst in and highlighting the instability theory," Journal of China Coal Society, vol. 16, no. 4, pp. 25-31, 1991.

[11] D. Ma, H. Duan, J. Liu, X. Li, and Z. Zhou, "The role of gangue on the mitigation of mining-induced hazards and environmental pollution: an experimental investigation," The Science of the Total Environment, vol. 664, pp. 436-448, 2019.

[12] Y. S. Pan and M. T. Zhang, "The exact solution for rockburst in coal mine by unstability rockburst theory," Chinese Journal of Rock Mechanics and Engineering, vol. 15, pp. 504-510, 1996.

[13] N. S. Nemat and H. Horii, "Compression-induced nonplanar crack extension with application to splitting, exfoliation, and rockburst," Journal of Geophysical Research: Solid Earth, vol. 87, no. B8, pp. 6805-6821, 1982.

[14] M. C. He, J. L. Miao, and J. L. Feng, "Rock burst process of limestone and its acoustic emission characteristics under truetriaxial unloading conditions," International Journal of Rock Mechanics and Mining Sciences, vol. 47, no. 2, pp. 286-298, 2010.

[15] D. Ma, H. Duan, Q. Zhang et al., "A numerical gas fracturing model of coupled thermal, flowing and mechanical effects," Computers, Materials \& Continua, vol. 65, no. 3, pp. 21232141, 2020.

[16] T. W. Lan, C. J. Fan, J. Han et al., "Controlling mechanism of rock burst by $\mathrm{CO}_{2}$ fracturing blasting based on rock burst system," Shock and Vibration, vol. 2020, Article ID 8876905, 9 pages, 2020.
[17] T. Lan, C. Fan, S. Li, H. Zhang, and A. S. Batugin, "Probabilistic prediction of mine dynamic disaster risk based on multiple factor pattern recognition," Advances in Civil Engineering, vol. 2018, Article ID 7813931, 6 pages, 2018.

[18] J. Han, H. W. Zhang, T. W. Lan, and S. Li, "Geodynamic environment of rockburst in western Beijing coalfield," Journal of China Coal Society, vol. 39, no. 6, pp. 1056-1062, 2014.

[19] H. W. Zhang, F. Zhu, and J. Han, "Geological dynamic conditions and forecast technology for rock bursts," Journal of China Coal Society, vol. 41, no. 3, pp. 545-551, 2016.

[20] J. Han and H. W. Zhang, "Fuzzy integrated estimation of fault activity in geology dynamic zoning," Chinese Journal of Geological Hazard and Control, vol. 18, no. 2, pp. 101-105, 2007.

[21] D. Ma, H. Duan, X. Li, Z. Li, Z. Zhou, and T. Li, "Effects of seepage-induced erosion on nonlinear hydraulic properties of broken red sandstones," Tunnelling and Underground Space Technology, vol. 91, Article ID 102993, 2019.

[22] H. W. Zhang, "Study of active faults and forecast of dynamic phenomena in mines," Journal of China Coal Society, vol. 23, no. 2, pp. 113-118, 1998.

[23] H. W. Zhang, K. X. Duan, J. G. Zhang, and L. U. Xin, "Study on the regional prediction of mining dynamic phenomenon," Journal of China Coal Society, vol. 42, no. 4, pp. 383-387, 1998.

[24] T. W. Lan, G. F. Su, and J. Han, "Prediction of coal and gas outburst based on geo-dynamic division," China Safety Science Journal, vol. 20, no. 3, pp. 46-50, 2010.

[25] H. W. Zhang and S. Li, "Pattern recognition and possibility prediction of coal and gas outburst," Chinese Journal of Rock Mechanics and Engineering, vol. 24, no. 19, pp. 3577-3581, 2005. 